Canadian Journal of Fisheries and Aquatic Sciences

Canadian

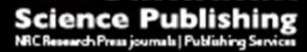

Journal canadien des sciences halieutiques et aquatiques

The theoretical foundations for size spectrum models of fish communities

\begin{tabular}{|r|l|}
\hline Journal: & Canadian Journal of Fisheries and Aquatic Sciences \\
\hline Manuscript ID & cjfas-2015-0230.R2 \\
\hline Manuscript Type: & Review \\
\hline Date Submitted by the Author: & $16-$ Nov-2015 \\
\hline Complete List of Authors: & $\begin{array}{l}\text { Andersen, Ken; Technical University of Denmark, National Institute of } \\
\text { Aquatic Resources } \\
\text { Jacobsen, Nis S; Technical University of Denmark, AQUA } \\
\text { Farnsworth, Keith; Queens University, Institute of Global Food Security }\end{array}$ \\
\hline Keyword: & $\begin{array}{l}\text { MARINE < Environment/Habitat, COMMUNITIES < General, ECOSYSTEMS } \\
\text { < General, MODELS < General }\end{array}$ \\
\hline
\end{tabular}

SCHOLARONE ${ }^{m}$

Manuscripts 


\section{The theoretical foundations for size spectrum models of fish}

\section{2 communities}

3 Ken H. Andersen ${ }^{1}$, Nis S. Jacobsen ${ }^{1}$ and K. D. Farnsworth ${ }^{2}$

4

${ }^{1}$ Center for Ocean Life, National Institute of Aquatic Resources (DTU-Aqua), Technical University of Denmark, Charlottenlund Castle, DK-2920, Charlottenlund, Denmark 2 Institute of Global Food Security, Queens University Belfast, 97 Lisburn Road, Belfast BT9 7BL, Northern Ireland, UK

9

\section{Abstract}

11 Size spectrum models have emerged from 40 years of basic research on how body size

12 determines individual physiology and structures marine communities. They are based

13 on commonly accepted assumptions and have a low parameter set, which make them

14 easy to deploy for strategic ecosystem oriented impact assessment of fisheries. We

15 describe the fundamental concepts in size-based models about food encounter and the

16 bioenergetics budget of individuals. Within the general framework three model types

17 have emerged that differs in their degree of complexity: the food-web, the trait-based

18 and the community model. We demonstrate the differences between the models

19 through examples of their response to fishing and their dynamic behavior. We review implementations of size spectrum models and describe important variations concerning

21 the functional response, whether growth is food-dependent or fixed, and the density-

22 dependence imposed on the system. Finally we discuss challenges and promising

23 directions. 
27 Marine community models range from the original Lotka-Volterra differential equations

28 to extremely complicated end-to-end simulations (Plagányi 2007; Fulton et al. 2011). In

29 the middle of the range we find size spectrum models. Size spectrum models use body

30 size of individuals to represent the entire fish community as a size distribution. The

31 reliance of body size simplify the description of predator-prey interactions, individual

32 physiology and vulnerability to fishing gear. This paper highlights one of the important

33 advantages of the size spectrum approach: a well-founded and unifying mechanistic

34 basis allowing for great explanatory power and parsimonious use of data.

Size spectrum models are relevant to fisheries science in the context of the ecosystem approach to fisheries management (Pikitch et al. 2004). While single-species stock assessments and impact assessment will continue to be important management tools, they need to be supplemented by strategic impact assessments at the level of the ecosystem. Such impact assessments assist the development and implementation of strategic long-term management goals for the ecosystem, e.g., how should fishing pressure be distributed over the entire ecosystem? How do we balance exploitation of competing fisheries such as forage fisheries and consumer fisheries? How do we maximize the yield (of biomass or wealth) of the entire ecosystem while minimizing risk of failure or impoverish components of the system under environmental change? To answer these questions, we need to quantitatively understand the relationship between fishing practice (what, when and how much) and the abundance of species and sizes of organisms throughout the community. 
53 life. This, combined with the strong relationship between body-size and trophic niche

54 (Barnes et al. 2008; Gilljam et al. 2011), means that individuals change their trophic

55 niche throughout ontogeny (Werner and Gilliam 1984). Such ontogenetic trophic niche

56 shifts makes it difficult to apply the conventional food-web approach, where each

57 species is described by a single metric (abundance or biomass) and a specific trophic

58 level, to fish communities. The relation between body size and trophic niche has

59 prompted the hypothesis that individual body size (rather than species identity) is the

60 primary determinant of community structure (Jennings et al. 2001).

Size spectrum models are based upon the long tradition in ecology of recognizing body size as a central trait to describe individuals (Elton 1927; Haldane 1928; Andersen et al. 2016a) because it correlates strongly with: metabolism (Kleiber 1932; Winberg 1956, Brown et al. 2004), predator-prey relations (Ursin 1973; Barnes et al. 2008), encounter rates (Acuña et al. 2011), functional responses (Rall et al. 2012), reproductive effort, and other vital rates (Peters 1983). For application to fisheries, body size furthermore is an excellent descriptor of mesh-size regulations and characterizes the value of a catch (Andersen et al. 2015). Finally, distributions of abundance vs. size show a remarkable regularity (Sheldon and Prakash 1972; Sheldon et al. 1977; Boudreau and Dickie 1992) and deviations from this regularity has been used to characterize ecosystem level impact of fishing (Rice and Gislason 1996; Daan et al. 2005). The size spectrum modeling paradigm promises a "charmingly simple" (Pope et al. 2006) set of tools with a low to intermediate complexity that can be readily deployed for a given system and provide quantitative information about the ecosystem impact of fishing (Collie et al. 2014). This makes it possible to apply the models in situations where more complex but

77 also data-demanding end-to-end models cannot be employed either because of lack of data or manpower to calibrate and run them. 
80 The various types of size spectrum model can be viewed as different developments of

81 the same core concepts. We review the common basic concepts behind size spectrum

82 models focusing on models that describe an entire fish community. Among them we

83 recognize three broad classes of decreasing levels of complexity. Most complex are the

84 'food-web' models, so called because they explicitly represent individual populations

85 with species-specific energy budget parameters and prey preferences, thereby

86 quantifying a network of trophic interactions as an explicit food-web. These are

87 simplified into the 'trait-based' models by reducing differences among the populations

88 to a single continuous variable representing a trait (usually maturation size) and

89 simplifying prey selection to a fixed predator-prey body size ratio. Further simplification

90 produces the 'community' size spectrum models, so called because they ignore

91 differences among populations thereby representing the community as a single

92 population of interacting individuals that differ only in their body-size. We explain how

93 the simpler models can be derived from the more complex, starting from the food-web

94 and ending with the community model. Further we develop analytical "equilibrium"

95 solutions to the models. We illustrate the models' behavior, in particular their response

96 to fishing, and finally discuss challenges and open issues for further development.

\section{Concepts underlying size spectrum models}

98 Size spectrum models are founded on three common concepts: First, biomass (and

99 equivalent energy) is conserved, enabling accountancy of energy flows at the

100 community level based on individual level processes. Second, trophic interactions are

101 the main determinant of community structure and these are foremost determined by

102 predator-prey size ratios. Third, the energy budget of an individual is allometrically

103 linked to body size, so that body size can be used as a key identifier of organisms and

104 their interactions with the community. The three main ecological processes for any

105 organism are growth, reproduction and mortality and all three can be linked to body 
106 size in this modeling framework. This simplification has great strategic value as it

107 enables ecological measures such as production rate and size structure (which are

108 important for ecosystem based fisheries management) to be derived from relatively

109 little and accessible data about physiology and life history invariants. The equations for

110 the models used in the examples to follow are provided in Table 1 and parameters in

111 Table 2.

113 The size spectrum

114 The size spectrum represents abundance or biomass of individuals as a function of their

115 body size. In this context 'body size' usually means body mass because it is the natural

116 metric to formulate an energy budget.

118 Three size spectrum representations are common in the literature (Sprules and Barth,

119 this issue; Andersen and Beyer 2006; Rossberg 2012): the abundance density spectrum,

120 the biomass density spectrum and the "Sheldon" biomass spectrum. The abundance

121 density spectrum $N(w)$ represents the number of individuals in the body mass range

122 from $w_{1}$ to $w_{2}$ as $\int_{w_{1}}^{w_{2}} N(w) \mathrm{d} w$, and here it is referred to as the size spectrum for brevity.

123 It can be constructed from observations by dividing the total number of individuals in a

124 size class by the width of the size class and therefore has dimensions of numbers per

125 mass (often referred to as the "normalized size spectrum"; Sprules and Barth, this

126 issue). The biomass density spectrum is constructed from the abundance density

127 spectrum by multiplying with body mass $N(w) w$ (dimensions biomass per mass). The

128 "Sheldon" biomass spectrum (Sheldon and Parsons 1967) is the biomass in

129 logarithmically wide classes, i.e., the biomass in the range $w$ to $c w$ where $c$ is a constant

130 larger than one determining the width of the size class. For example, the "octave" bin

131 used by Sheldon implies $c=2$, and normal $\log 10$ base implies $c=10$. If we assume that

132 the abundance density spectrum follows a power-law $N(w)=\kappa w^{\lambda}$ within the class then 
133 the biomass spectrum can be found as:

$$
B_{\log }(w)=\int_{w}^{c w} N(\omega) \omega \mathrm{d} \omega=\kappa \frac{c^{2+\lambda}-1}{2+\lambda} w^{2+\lambda} \propto w^{2} N(w)
$$

137 where $\omega$ is a dummy variable for the integration. All terms except $w^{2+\lambda}$ are independent

138 of size, hence the biomass spectrum is proportional to the number density spectrum

139 multiplied by the body mass squared. For mathematical analyses the density spectra are

140 convenient because integrals over these give the abundance and biomass. For

141 presentation purposes the Sheldon biomass representation $w^{2} N(w)$ is convenient

142 because, at the community level, it shows how the biomass of prey is distributed with

143 size (assuming that the size range of preferred prey is constant), and on a species level it

144 is proportional to the cohort biomass.

Conservation equation

147 The size spectrum is calculated by considering a balance between mortality and growth 148 at all body sizes $(w)$. Individuals flow into size classes via somatic growth whilst some 149 are lost to natural and fisheries mortality. This balance is formalized by the McKendricvon Foerster equation (see Silvert and Platt (1978) for a derivation):

$$
\frac{\partial N_{i}(w)}{\partial t}+\frac{\partial g_{i}(w) N_{i}(w)}{\partial w}=-\mu_{i}(w) N_{i}(w)
$$

154 where $g_{i}(w)$ is the growth rate (mass per time) and $\mu_{i}(w)$ the mortality (per time), and

$155 N_{i}(w)$ is the size spectrum of species $i$. Thus eq. (1) scales from individual-level

156 processes of growth and mortality to the population-level size spectrum. Recruitment

157 from the population flows into the size spectrum at the smallest body size (typically the

158 egg size) $w_{0}$. This is represented as a boundary condition: 


$$
g_{i}\left(w_{0}\right) N_{i}\left(w_{0}\right)=R_{i}
$$

where $R_{i}$ is the recruitment (number of recruits or eggs per time). The above two

equations are mathematical formalizations of a mass balance, and can be thought of as the size-based version of classic survivor analysis used in age-based models.

The following outlines the central assumptions in the models about how growth $g_{i}$, mortality $\mu_{i}$ and reproduction (recruitment) $R_{i}$, are calculated. With the partial exception of recruitment these are all calculated from individual level processes of predator-prey encounter and a bioenergetic budget (Figure 1).

The Andersen-Ursin encounter model

The key process in the models is predator-prey encounters between individuals governed by a formalization of the general rule, bigger fish eat smaller fish (Andersen

174 and Ursin 1977). Individuals prefer prey a certain fraction smaller than themselves (M1,

175 Table 1) (Ursin 1973). The clearance rate (dimensions time-1) is an increasing function 176 of body size (larger fish clear a larger volume of water for prey per time than small fish)

177 (M2). The combination of preference, clearance rate and prey abundance specifies the 178 food encounter rate (M3, biomass per time). Intake upon encounter ("satiation") is 179 represented with a type II functional response (M5) as the "feeding level" $f_{i}(w)$, i.e., the 180 ratio between consumption and maximum consumption (M4) (dimensionless number 181 between 0 and 1 ).

\section{Individual energy budget}

184 The energy budget describes how consumed food is used for maintenance, activity, 185 growth and reproduction. Consumed food is assimilated and first used for standard 
metabolism, widely recognized to be an allometric function of body mass: $k_{s} w^{p}$. Juvenile

187 individuals use the remaining available energy for growth, while mature individuals

188 apportion the energy between growth and reproduction (M6-M8). The exact

189 specification of allocation of energy between growth and reproduction is not crucial.

190 The one used here ensures that when the feeding level is constant, size-at-age curves

191 resembles a von Bertalanffy curve and the gonado-somatic is independent of body size

192 (Hartvig et al. 2011).

Reproduction and recruitment

Reproduction and recruitment represent the reproductive output from the entire population. The reproductive output $R_{\mathrm{p} . i}$ (numbers per time; M9) is discounted by a reproductive efficiency $\varepsilon$ to represent losses due to egg mortality and spawning effort, and used to calculate the recruitment $R_{i}$. Within this context, recruitment refers to the rate of production of new individuals from the fertilized egg stage, but it could be done at a later stage if properly discounted (Andersen and Beyer 2015). Ideally the

201 recruitment is equal to the reproductive output, but many models apply a stock recruitment relationship (M10). The density dependence imposed by the stock

203 recruitment relationship avoids the competitive exclusion between species that

204 otherwise tends to occur (Hartvig and Andersen 2013). The stock-recruitment

205 relationship contains two essential parameters: the "slope" parameter that specifies

206 recruitment at low population sizes and the maximum recruitment that specifies the

207 population carrying capacity. The slope parameter is given directly by the egg

208 production of the population (Andersen and Beyer 2015), but the maximum recruitment

209 has to be specified separately. This parameter represents all effects on the population

210 that are not explicitly represented in the model, such as limitations due to juvenile

211 habitat size that is known to limit some marine populations (Rijnsdorp and Leeuwen 
212 1992). The maximum recruitment and possibly the recruitment efficiency are key

213 parameters for calibrating a model to data from real fish stocks (see discussion).

215 Mortality

216 Three categories of mortality are recognized. First, predation mortality (M13) emerges

217 from the trophic dynamics within the system; second, intrinsic or background mortality

218 (M12) is usually represented as an allometric function of asymptotic size (Brown et al.

219 2004), though starvation mortality can be explicitly added (e.g., Hartvig et al. 2011);

220 third, exogenous sources of mortality (especially fishing) are often added.

Resource

223 The resource spectrum $N_{R}(w)$ represents food other than fish. The resource is needed

224 for the smallest individuals who are not yet large enough to be piscivorous but it can

225 represent any kind of food: a single size-group of small zooplankton prey species, a size

226 spectrum of zooplankton prey (as in Fig. 1), or a size distribution including larger prey,

227 e.g. benthic production. The resource can be constant, in which case the growth rate of

228 small fish is fixed, or it can be modeled dynamically, e.g., as a semi-chemostat (M14). The

229 semi-chemostat formulation is convenient because it leads to a very stable dynamics of

230 the resource. Using logistic growth results in a more pronounced dynamical response of

231 the resource which translate into stronger dynamics of the fish part of the model (de

232 Roos et al. 2008).

\section{Models types}

234 We now briefly describe how these common concepts are used to create size spectrum

235 models at three levels of complexity and demonstrate an approximate analytical

236 solution for the equilibrium. 
239 In the food-web model, the processes M1 - M15 are instantiated with all parameters

240 from Table 2 being species specific (either representing identified species or

241 hypothetical ones matching relevant criteria), but in practice some parameters are

242 usually cross-species constants, such as the exponents $n, p$ and $q$. Populations, thus

243 identified as different species, interact through predator-prey relations with interaction

244 strengths specified by an interaction matrix, which represents a combination of species-

245 specific preferences and encounter probabilities. This matrix could be populated with

246 empirical interaction coefficients derived from stomach content analyses, spatial

247 overlap (Blanchard et al. 2014), or it may represent hypothetical distributions -- random

248 and uniform (everything eats everything else) interaction networks are popular

249 hypotheses. A fully specified food-web model has 14 parameters for each species, plus

250 an interaction matrix, so for $k$ species the total is up to $3+14 k+k^{2}$ parameters.

Trait-based model

253 The trait-based model represents differences among species only by the governing trait

254 of asymptotic size (Pope et al. 2006). This assumes that the most important trait is the

255 asymptotic size (or, equivalently, size at maturation), which embodies a trade-off

256 between reproductive output and asymptotic size. The trait-based model is

257 conceptually derived from the food-web model by assuming that all parameters in Table

2582 are cross-species constants and by using theoretical arguments to determine $R_{\max }$ as a

259 function of $W$ (appendix A). Feeding interaction are solely determined by individual

260 size. The solution is the trait size spectrum $N(w, W)$ (dimensions numbers per mass per

261 asymptotic mass) describing the joint distribution of individual and asymptotic sizes

262 (Andersen and Beyer 2006). In numerical implementations the asymptotic size axis is

263 discretized, typically into logarithmic 'bins' grouping species in asymptotic size classes.

264 In practice, the results of the trait-based model are effectively independent of the 
265 number of simulated asymptotic size classes once this number is greater than 10 . The 266 trait-based model is specified with the 18 parameters in Table 2.

Community model

269 The community model ignores all differences between species and only considers 270 differences in size (Benoît and Rochet 2004). It can be derived from the trait-based and 271 food-web models by integrating over all trait-classes or summing over species (Zhang et 272 al. 2012):

$$
N_{c}(w)=\int_{w}^{\infty} N(w, W) \mathrm{d} W=\sum_{i=1} N_{i}(w) .
$$

276 The integral only runs from $w$ because asymptotic size groups with $w<W$ does not 277 contribute to the community spectrum at size $w$. The community model only resolves 278 the 'community spectrum' $N_{c}(w)$. Substantial consequences arise because this model is 279 unable to represent maturation, reproduction and recruitment. The energy budget (M6280 M8) is simplified such that growth is solely available energy multiplied by an "average 281 growth efficiency" derived from equilibrium theory (M7b; Appendix A). Because 282 energetic losses to reproduction are not explicitly accounted for, the model will not 283 reproduce von Bertalanffy growth. Further, most implementations in the literature use 284 just a linear functional response, ignore standard metabolism and use a fixed resource 285 (Table 3), however, these simplifications are not significant for the community model. In 286 its most comprehensive form, the community model requires only 11 parameters (less without the functional response and with fixed resource). 
290 Analytical solutions to the trait-based model can be derived under the assumption that

291 the feeding level is constant $f(w)=f_{0}$ and that the spectrum is infinitely long, i.e. $w_{0}=$

2920 and $\max (W)=\infty$ (Andersen and Beyer 2006; Hartvig et al. 2011). This results in an

293 'equilibrium community spectrum':

294

295

$$
N_{c}(w)=\frac{1}{\Phi} \frac{f_{0}}{1-f_{0}} \frac{h}{\gamma} w^{n-2-q}(3)
$$

296

with $\left.\Phi=\sqrt{2 \pi} \sigma \beta^{q-n} \exp \left[(q-n)^{2} \sigma^{2} / 2\right)\right]$. The scaling exponent $n-2-q \approx-2.05$ is in

accordance with observations (Boudreau and Dickie 1992). The equilibrium solution for

each species spectrum is:

$$
N(w, W) \propto \kappa W^{2 n-q-3+a} w^{-n-a}\left[1-\left(\frac{w}{W}\right)^{1-n}\right]^{a /(1-n)}
$$

with the "physiological mortality" a given in (M17). This result is used to calculate

expected scaling solutions to predation mortality, the scaling of maximum recruitment

304 with asymptotic size used in the trait-based models, and the average growth efficiency

305 in the community model (Appendix A). Note that the solution in eq. (4) does not fulfill

306 the boundary condition (M9); the total reproductive output calculated from (4) will lead

307 to a life-time reproductive output larger than 1 and increasing with asymptotic size

308 (discussed in Hartvig et al. 2011 and Rossberg 2012). This discrepancy has to be

309 resolved by density-dependent effects within each population not accounted for in (4),

310 and it has been used to relate the slope parameter in stock-recruitments relationship to

311 asymptotic size (Andersen and Beyer 2015). In the dynamical models the emergent

312 physiological mortality depends on asymptotic size, with smaller species having a

313 smaller $a$ than larger (Hartvig et al. 2011), in accordance with empirical measurements

314 of how mortality depends on asymptotic size (Gislason et al. 2010). Even though (4) is 
315 not an exact solution of the entire model, it is still a useful approximation, as

316 demonstrated by its ability to resolve species diversity (Reuman et al. 2014).

317

318 The equilibrium results all rely on the metabolic assumption inherent in the functional

319 response where consumption is proportional to $w^{n}$. If a functional response is not used

320 the solution for the exponent of the community spectrum will differ from eq. (3). In

321 particular it will not depend on the metabolic exponent $n$, but rather on the preferred

322 predator-prey mass ratio $\beta$ (Benoît and Rochet 2004; Datta et al. 2010; Rossberg 2012).

323 Such solutions will result in consumption rates that do not follow metabolic scaling.

Parameters

326 Parameters are either determined from knowledge about the specific species (for the 327 food-web model), or from cross-species investigations of life-history invariants (Table

328 2; see Hartvig et al. (2011), App E. for a detailed discussion). The relatively small set of 329 parameter facilitates formal investigations of model behavior under varying parameter 330 values (Thorpe et al. 2015; Zhang et al. 2015).

Implementation

333 Size spectrum models may be simulated with "Mizer", a reference implementation in R 334 (Scott et al. 2014), or with the matlab code (see online supplementary). For the food335 web model we have used the parameterization for the North Sea (Blanchard et al. 2014), 336 which uses $n=2 / 3$ as is customary in the fisheries literature. For the trait-based and 337 community models we have used $n=3 / 4$ to conform with "metabolic" theory (West et 338 al. 2001). The results are qualitatively sensitive to the value of $n$ as long as it is changed 339 in all the relationships in Table 1 . The community model has been implemented as a 340 trait-based model with a single trait group having a very large asymptotic size. As the 341 individuals in the trait group mature their growth rate declines (Fig. 2d). In this way the 
342 average growth in the community model corresponds to the average growth in a trait-

343 based model. Our implementation avoids the need for an additional senescent mortality

344 for the largest individuals as is common practice (Law et al. 2009; Rochet and Benoît

345 2012).

347 All simulations are set up with 100 logarithmically spaced grid points on the mass axis, 348 with the first grid point set to egg size w0. Each simulation was run with a time step of 3490.25 year until convergence (Appendix B).

\section{Example simulations}

351 All three models predict size spectra, growth rates and mortality (Figure 2). In the

352 absence of fishing and top predators the largest size groups ( $w>10 \mathrm{~kg}$ ) are

353 superabundant, i.e., that part of the spectrum is greater than predicted by the

354 equilibrium solution. This is most pronounced in the food-web model, and could be 355 changed by increasing the background mortality $Z_{0}$. The superabundance results in 356 higher predation mortality on medium-sized individuals, which triggers a trophic 357 cascade and associated changes in growth and mortality of smaller individuals 358 (Andersen and Pedersen 2010).

Responses to fishing

361 The behavior of the models is illustrated by examining the response of the time-

362 averaged solution to fishing and their dynamical behavior. Fishing using size-selective

363 gear is represented by adding a fishing mortality that depends on body size, and

364 possibly also asymptotic size or species. We illustrate fishing through two scenarios: a)

365 community-wide fishing on all species with a trawl-type selectivity pattern having $50 \%$

366 selectivity at $0.05 \mathrm{~W}$, and b) a bottom-up perturbation where forage fishery is removed

367 from scenario (a) simulated by setting fishing mortality zero on all species with $W<$ 
$368200 \mathrm{~g}$ in the food-web and trait-based models and on individuals with $w<200 \mathrm{~g}$ in the

369 community model (Figure 3). In scenario (a) (community wide fishing) the reduction of

370 large individuals induces a trophic cascade throughout the community seen as a wave in

371 the size spectrum. When forage fishing is removed (b), the food-web and trait-based

372 models predict an increase of forage fish but relatively modest effects on the rest of the

373 community. The forage fish have a higher biomass than in the unfished situation due to

374 the partial release from predation by higher trophic levels caused by fishing. The

375 response of the community model is different: it predicts a decline in the size-range

376 where fishing is removed, while the effects on the rest of the community are weak, as in

377 the other models. This difference in the community models stems from its inability to

378 represent fishing (or, in this case, absence of fishing) on specific species or life histories,

379 but only on body sizes. This result emphasizes the importance of representing

380 individual populations in fisheries applications. The two scenarios illustrates the

381 relative importance of mortality and growth to mediate trophic cascades: in scenario (a)

382 the trophic cascade is mainly mediated by changes in predation mortality, which leads

383 to a strong cascade. In scenario (b) increases in forage fish abundance has two effects

384 with opposite consequences: 1) it increases growth rates of larger individuals, but 2) it

385 also increases competition between juvenile individuals of larger species and forage fish

386 leading to decreased growth rates. The end result is a modest trophic cascade (Houle et

387 al. 2013; Jacobsen et al. 2015). The importance of competition between forage fish and

388 juvenile predatory fish in real ecosystems could be analyzed by comparing stomach

389 contents of forage fish and juvenile predatory fish. In summary: the food-web and trait-

390 based models predict similar response to selective fishing, while the community model

391 fails to resolve effects on different populations. 
394 The community model also differs from the food-web and trait-based model in

395 dynamical behavior, i.e., how the solution varies over time. All models tend to be

396 unstable (oscillate over time) if the trophic overlap is small. The trophic overlap is

397 determined by the ratio between the width of the size preference function, $\sigma$, and the

398 predator-prey size ratio $\log (\beta)$ : the smaller the value of $\sigma / \log (\beta)$, the smaller the

399 trophic overlap, and the more unstable the solution becomes (larger oscillations) (Datta

400 et al. 2011; Zhang et al. 2012) (Figure 4). Oscillations in the trait-based models are fairly

401 modest, but the community model is prone to unrealistically strong non-linear

402 dynamics: the solution varies by up to 10 orders of magnitude (Figure $4 \mathrm{~b}$ and d). This

403 means that some parts of the spectrum alternate between being completely devoid of

404 fish and being fully populated. It is therefore evident that the non-linear properties of

405 the community model are fundamentally different from the models with life-history

406 diversity, such as the trait-based models or a food-web model. Even if the community

407 model is made linearly stable with a high trophic overlap or a diffusion term (Datta et

408 al., 2011), the strong dynamical response will still be present if the model is perturbed

409 away from the equilibrium. This should be kept in mind if the model is used to simulate

410 the dynamical behavior of marine ecosystems (Zhang et al. 2012; Rossberg 2013 p. 273).

\section{Challenges and open issues}

412 Size spectrum models distinguish themselves from unstructured models by resolving

413 individual body size as a continuous state variable (body size). To what extent do

414 individual body size and species identity determine the ecological outcomes of

415 community dynamics? The thrust of size spectrum modeling has become an emphasis

416 on the former, whilst unstructured models have emphasized the latter. Some size

417 spectrum models represent species interactions, and some attempts have been made to

418 find a common understanding between the two perspectives. Notably, a food-web model

419 with implicit representation of intra-species size structure was obtained (Rossberg and 
420 Farnsworth 2011) to (indirectly) describe interactions among species of different sizes.

421 The importance of explicitly resolving the size-structure of species, or where it can

422 safely be ignored, is context dependent so requires specific and systematic exploration

423 (Jacobsen et al. 2015; Woodworth-Jefcoats et al. 2015).

425 An important difference between implementations of size spectrum models is whether

426 growth is fixed or food-dependent (Table 3). Fixing growth simplifies model setup and

427 calibration. It is justified by the modest variations in growth observed in marine species.

428 Fixing growth, however, has consequences which should be considered when the model

429 is calibrated and results are interpreted. A model with fixed growth will still resolve

430 trophic cascades mediated by mortality, but it will not resolve competition, which is

431 crucial to describe the phenomenon of overcompensation (De Roos and Persson 2002)

432 and may be important to understand the response of the spectrum to, e.g. fishing on

433 'forage' species (Houle et al. 2013; Jacobsen et al. 2015). More importantly, without

434 food-dependent growth, the mass balancing between growth and predation mortality is

435 broken. This requires that care is taken in the setup to ensure that predation mortalities

436 are in the correct range by adjusting the "other food" compartment (Thorpe et al. 2015).

437 Having too low predation mortalities (as in Hall et al. 2006; Worm et al. 2009; Rochet et

438 al. 2011) will result in a model that is essentially a set of weakly coupled single-species

439 models thus defying the purpose of a multi-species model.

441 Size-based models have been characterized as "highly unrealistic" and being based on

442 "unrealistic and even contradictory assumptions" (Froese et al. 2015; Andersen et al.

443 2016b). We hope to have made it clear that the basic assumptions are realistic and

444 internally consistent. Nevertheless, while the size-based models have matured to a

445 degree where they can be applied to make impact assessments of fishing on marine

446 ecosystems, they still face challenges related to density-dependence, life-history trade- 
447 offs, termination at the large body sizes end, calibration procedure, and numerical

448 implementation, which must be confronted: each will be briefly discussed.

Density dependence

451 All food-web models of real ecosystems, i.e. with specific species, require some form of

452 density dependent regulation of the abundance of each species to avoid competitive

453 exclusion. Not much is known about the exact mechanism of the regulation and how

454 different mechanisms affect model results. The size based interactions and trait

455 differences among species in size spectrum models provide insufficient niche

456 differentiation to avoid competitive exclusion (Hartvig and Andersen 2013). Additional

457 niche differentiation may be represented by a random species-specific interaction

458 matrix, which can support coexistence (Hartvig 2011; Hartvig et al. 2011). Other

459 commonly used mechanisms are (Table 3): stock-recruitment relationships; fixed

460 recruitment; predator-dependent functional responses, whereby intake depends on the

461 density of competitors as well as prey (also used in Ecosim) (Abrams 2014); and prey

462 switching (Maury and Poggiale 2013), whereby rare prey are not attacked (leading to an

463 emergent type III functional response). Which of these mechanisms is the most correct

464 representation of effects in real ecosystem is currently unknown: stock-recruitment

465 relations and fixed recruitment are in line with standard practice in fisheries science,

466 but have little theoretical support; predator-dependent functional responses and prey

467 switching certainly occur to some extent, but the understanding is currently too weak to

468 make general statements of the strength of the processes. Within structured models,

469 such as size spectrum models, the type of density dependent regulation may have a

470 profound impact on the solution, both the size spectrum of the individual species and

471 the relative abundances of species (compare Fig. 4 in Maury and Poggiale (2013) with

472 Figure 2B). As an example, we tested the prediction from the trait-based model against

473 empirical observations by comparing the asymptotic size distribution with observations 
474 from three trawl surveys in the North Sea (Daan et al. 2005) (Figure 5). Even though the 475 comparison does not reject the modeled distribution, more comparisons with similar 476 data from other systems are needed to build confidence in the predicted asymptotic size 477 distributions.

In addition to ensuring coexistence of species, the imposed density dependence also acts as a carrying capacity. In the food-web model the carrying capacity $\left(R_{\max }\right)$ is found by calibrating to observed biomasses. The trait-based model, however, relies on theoretical results from the equilibrium theory. That theory compares favorably to the calibrated results (Figure 6). Nevertheless, the use of a stock-recruitment relationship is unsatisfactory as it introduces a dominating external regulation on the biomass of species. This may bias the response time of community size structure (Fung et al. 2013), which is of interest in conservation. Further, the stock-recruitment relationship means that a large amount of spawned biomass is simply lost to unspecified density-dependent processes. The stock-recruitment relationship therefore breaks the mass-balancing which is carefully observed in the other processes in the model (Persson et al. 2014).

490 Since there is no generally accepted solution to the problem of maintaining coexistence,

491 results should be interpreted in light of the assumptions used to represent density 492 dependent regulation. It must be emphasized that this problem is common to all food493 web models and not unique to size spectrum models.

Traits and trade-offs The trait-based model assumes that the most important trait is the asymptotic size. Fish, however, vary in other traits than asymptotic size. The questions are then: which other trait(s) should be included in a model to represent observed variation? And how can

499 suitable trade-offs be formulated and parameterized? An obvious trait is activity.

500 Increased activity causes higher prey encounter rates (higher value of the clearance rate 
501 constant, $\gamma$ ). On the other hand, higher activity results in increased metabolic rates and

502 increased vulnerability due to higher exposure to predators. It is possible that inclusion

503 of an activity trait would make it possible to distinguish sedentary from active species

504 with the same asymptotic size, such as anglerfish and scombroids. Such a trait may not

505 solve the problem of competitive exclusion because it does not lead to sufficient niche

506 differentiation. A trait which would lead to niche differentiation could be related to

507 habitat (Hartvig 2011; Zhang et al. 2013), i.e., pelagic vs. benthic (Blanchard et al. 2011).

508 In both cases more theoretical investigations are needed but also empirical work to

509 establish and parameterize the trade-offs.

510

511 Closure of the spectrum at large body sizes

512 An overlooked issue is the termination (closure) of the model spectrum at the largest

513 body sizes. Closure is usually achieved (rather arbitrarily) by choosing a maximum body

514 size and enforcing some background mortality to kill of the largest individuals.

515 However, the size of this mortality clearly influences the results, in particular in the un-

516 fished situation. In the simulations presented here (Figure 2), this background mortality

517 is relatively low, leading to the superabundance of large individuals compared to the

518 equilibrium solution. However, we do not know the real abundance of the largest

519 individuals in an unfished system, because most systems are heavily perturbed.

520 Further, what is the theoretical largest size of a fish? Why are teleost fish not larger than

521 a few hundred kg? There is no physiological mechanism in the model to limit the

522 asymptotic size, and current theoretical understanding can only guess at an answer to

523 this question (Freedman and Noakes 2002; Andersen et al. 2008; Andersen et al. 2016a).

524 A satisfactory theoretical understanding of the factors limiting the upper size of fish is

525 needed to bolster the consistency of the models.

526

527 Calibration to real systems 
528 Size based models can be calibrated to real ecosystems, for instance on the scale of a 529 continental shelf (in smaller systems immigration / emigration violate the assumed 530 population closure). In the trait-based models calibration is achieved by varying some

531 of the crucial parameters, such as the growth rate parameter $h$ and the carrying capacity

532 of the resource to reproduce observed average growth rates of individuals and eco-

533 system level catch rates of the fishery (Pope et al. 2006; Kolding et al. 2015). The next

534 level of sophistication is to match modeled species to known species characteristics

535 (Jacobsen et al. 2015), and further to include a species interaction matrix (Hall et al.

536 2006; Blanchard et al. 2014). In these cases the biomass of each species has to be

537 calibrated by adjusting $R_{\max }$. Another important parameter that hitherto has been

538 ignored is the reproductive efficiency $\varepsilon$. This parameter represents egg survival, which

539 is likely to vary substantially between species. Introducing yet another calibration

540 parameter, however, requires more data. Currently, the calibration methods applied are

541 statistically simple. A more sophisticated approach acknowledges uncertainty by

542 creating an ensemble of plausible models, requiring them to fulfill general criteria

543 (Thorpe et al. 2015). A possible future direction could be introduction of a full statistical

544 framework where distributions of parameter values are derived from observations of

545 biomasses and stomach content by maximizing a likelihood function (Lewy and Vinther

546 2004; Spence et al. 2015). Finally, it should be kept in mind that even though a model

547 may be well calibrated to current situations there is no guarantee that it will reliably

548 predict the future.

Numerical solution procedure

551 Gains in accuracy and speed of the numerical solution may be achieved by moving to

552 more advanced methods. The standard method is a first-order semi-implicit upwind

553 scheme that is simple to implement (Appendix B). The drawback of this method is that it

554 has numerical diffusivity, is not very efficient, possibly inaccurate for dynamics, and is 
555 unable to resolve "cohort cycles" (de Roos and Persson 2001) with discontinuities in the

556 solution in the form of "shocks". To move forward, we recommend looking in the rich

557 literature from computational fluid mechanics for inspiration, in particular towards

558 higher order finite-volume techniques with limiters, which maintains positivity of the

559 solution (Zijlema 1996), or spectral methods (Rossberg 2012). Enhancements to the

560 numerical scheme could be implemented to common benefit in the (open access)

561 reference implementation "Mizer" (Scott et al. 2014).

562

Current and future applications

564 We have shown how size spectrum models can be used to simulate how fishing of one

565 group of species affects the entire system and that is very difficult to achieve with

566 alternative models. Despite several open issues in size-based modeling, as discussed

567 above, the model framework has already shown its use to: illustrate how fishing drives

568 trophic cascades (Andersen and Pedersen 2010), simulate the impact of rising

569 temperatures (Maury et al. 2007; Pope et al. 2009), explore the potential impacts of

570 climate change scenarios on fish production (Blanchard et al. 2012; Woodworth-Jefcoats

571 et al. 2013; Barange et al. 2014; Lefort et al. 2014), describe the indirect effect of

572 ecosystem recovery strategies (Andersen and Rice 2010), quantify the interaction

573 between forage and consumer fishery fleets (Engelhard et al. 2013; Houle et al. 2013) or

574 between fisheries and marine mammals (Houle et al. 2015), evaluate ecosystem fishing

575 strategies and indicators (Houle et al. 2012; Blanchard et al. 2014; Jennings and

576 Collingridge 2015; Spence et al. 2015; Thorpe et al. 2015), evaluate balanced harvesting

577 (Rochet et al. 2011; Jacobsen et al. 2014; Law et al. 2014) and describe the ecosystem

578 level yield (Worm et al. 2009; Andersen et al. 2015). Other obvious uses would be as

579 operating models in management strategy evaluations, as the basis for bio-economic

580 evaluations of fishing on the entire community (Andersen et al. 2015), and to further

581 developing our basic understanding of fish community functioning. In our view, the 
582 community model is best limited to theoretical work examining the steady-state

583 solutions. The trait-based model can be quickly deployed in data-poor situations and

584 makes a flexible tool for exploration of community-level fishery interactions. The food-

585 web types of models are well suited to more specific fisheries questions where a higher

586 level of species identity is needed than provided by the trait-based model. Besides these

587 strategic applications, it is tempting to deploy size spectrum models for tactical

588 ecosystem based management, e.g., for providing advice on specific species. We are

589 reluctant to endorse such uses because we find the purely process-oriented framework

590 too rigid to provide precise quantitative information on the species level. In conclusion:

591 the small number of parameters, the low computational requirements and the solid

592 mechanistically basis provide a framework of low to intermediate complexity, highly

593 suited to the strategic impact assessment of pressures such as fishing and

594 environmental change on marine ecosystems.

595 


\section{Acknowledgements}

598 We thank Julia L. Blanchard and Axel Rossberg for comments on the manuscript. This

599 work was supported by the Centre for Ocean Life, a VKR Centre of Excellence supported 600 by the Villum Foundation.

601

602

603

604

605

606

607

608

609

610

611

612

613

614

615

616

617

618

619

620

621

622

623

624

625

626

627

628

629

\section{References}

Abrams, P.A. 2014. Why ratio dependence is (still) a bad model of predation. Biol. Rev. 90: 794-814. doi: 10.1111/brv.12134.

Acuña, J.L., López-Urutia, Á., and Colin, S. 2011. Faking giants: the evolution of high prey clearance rates in jellyfishes. Science 333: 1627-1629.

Andersen, K.H., Berge, T., Gonçalves, K.H., Hartvig, M., Heuschele, J., Hylander, S., Jacobsen, N.S., Lindemann, C., Martens, C., Neuheimer, A.B., Olsson, A.B., Palacz, A., Prowe, F., Sainmont, J., Traving, S.J., Visser, A.W., Wadhwa, N., and Kiørboe, T. 2016a. Characteristic sizes of life in the oceans, from bacteria to whales. Ann. Rev. Mar. Sci. doi: 10.1146/annurev-marine-122414-034144.

Andersen, K.H., and Beyer, J.E. 2006. Asymptotic size determines species abundance in the marine size spectrum. Am. Nat. 168: 54-61.

Andersen, K.H., and Beyer, J.E. 2015. Size structure, not metabolic scaling rules, determines fisheries reference points. Fish Fish. 16(1): 1-22. doi: 10.1111/faf.12042.

Andersen, K.H., Beyer, J.E., Pedersen, M., Andersen, N.G., and Gislason, H. 2008. Life-history constraints on the success of the many small eggs reproductive strategy. Theor. Popul. Biol. 73(4): 490-7. doi: 10.1016/j.tpb.2008.02.001.

Andersen, K.H., Blanchard, J.L., Fulton, E.A., Gislason, H., Jacobsen, N.S., and van Kooten, T. 2016b. Assumptions behind size-based ecosystem models are realistic. ICES J. Mar. Sci. doi: doi:10.1093/icesjms/fsv211.

Andersen, K.H., Brander, K., and Ravn-Jonsen, L. 2015. Trade-offs between objectives for ecosystem management of fisheries. Ecol. Appl. 25: 1390-1396.

Andersen, K.H., and Pedersen, M. 2010. Damped trophic cascades driven by fishing in model marine ecosystems. Proc. R. Soc. London B 277: 795-802.

Andersen, K.H., and Rice, J.C. 2010. Direct and indirect community effects of rebuilding plans. ICES J. Mar. Sci. 67(9): 1980-1988.

Andersen, K.P., and Ursin, E. 1977. A multispecies extension to the Beverton and 
630

631

632

633

634

635

636

637

638

639

640

641

642

643

644

645

646

647

648

649

650

651

652

653

654

655

656

657

658

659

660

661

662

663

664

665

666

Holt theory of fishing, with accounts of phosphorus circulation and primary production. Meddelelser fra Danmarks Fisk. og Havundersøgelser 7: 319-435.

Barange, M., Merino, G., Blanchard, J.L., Scholtens, J., Harle, J., Allison, E.H., Allen, J.I., Holt, J., and Jennings, S. 2014. Impacts of climate change on marine ecosystem production in societies dependent on fisheries. Nat. Clim. Chang. 4(3): 211-216. doi: 10.1038/NCLIMATE2119.

Barnes, C., Bethea, D.M., Brodeur, R.D., Spitz, J., Ridoux, V., Pusineri, C., Chase, B.C., Hunsicker, M.E., Juanes, F., Kellermann, A., J., L., Ménard, F., Bard, F.X., Munk, P., Pinnegar, J.K., Scharf, F.S., Rountree, R.A., Stergiou, K.I., Sassa, C., Sabates, A., and Jennings, S. 2008. Predator and prey body sizes in marine food webs. Ecology 89(3): 881.

Benoît, E., and Rochet, M.-J. 2004. A continuous model of biomass size spectra governed by predation and the effects of fishing on them. J. Theor. Biol. 226(1): 9-21. doi: 10.1016/S0022-5193(03)00290-X.

Beverton, R.J.H. 1992. Patterns of reproductive strategy parameters in some marine teleost fishes. J. Fish Biol. 41: 137-160.

Blanchard, J.L., Andersen, K.H., Scott, F., Hintzen, N.T., Piet, G., and Jennings, S. 2014. Evaluating targets and trade-offs among fisheries and conservation objectives using a multispecies size spectrum model. J. Appl. Ecol. 51(3): 612622. doi: 10.1111/1365-2664.12238.

Blanchard, J.L., Jennings, S., Holmes, R., Harle, J., Merino, G., Allen, J.I., Holt, J., Dulvy, N.K., and Barange, M. 2012. Potential consequences of climate change for primary production and fish production in large marine ecosystems. Philos. Trans. R. Soc. Lond. B. Biol. Sci. 367(1605): 2979-89. doi: 10.1098/rstb.2012.0231.

Blanchard, J.L., Jennings, S., Law, R., Castle, M.D., McCloghrie, P., Rochet, M.-J., and Benoit, E. 2009. How does abundance scale with body size in coupled sizestructured food webs? J. Anim. Ecol. 78(1): 270-80. doi: 10.1111/j.13652656.2008.01466.x.

Blanchard, J.L., Law, R., Castle, M.D., and Jennings, S. 2011. Coupled energy pathways and the resilience of size-structured food webs. Theor. Ecol. 4(3): 289300. doi: 10.1007/s12080-010-0078-9.

Boudreau, P.R., and Dickie, L.M. 1992. Biomass spectra of aquatic ecosystems in relation to fisheries yield. Can. J. Fish. Aquat. Sci. 49(8): 1528-1538.

Brown, J.H., Gillooly, J.F., Allen, A.P., Savage, V.M., and West, G.B. 2004. Toward a metabolic theory of ecology. Ecology 85(7): 1771-1789.

Collie, J.S., Botsford, L.W., Hastings, A., Kaplan, I.C., Largier, J.L., Livingston, P. a, 
667

668

669

670

671

672

673

674

675

676

677

678

679

680

681

682

683

684

685

686

687

688

689

690

691

692

693

694

695

696

697

698

699

700

701

702

703

Plagányi, É., Rose, K. a, Wells, B.K., and Werner, F.E. 2014. Ecosystem models for fisheries management: finding the sweet spot. Fish Fish. doi:

10.1111/faf.12093.

Daan, N., Gislason, H., Pope, J.G., and Rice, J.C. 2005. Changes in the North Sea fish community: evidence of indirect effects of fishing? ICES J. Mar. Sci. 62(2): 177-188. doi: 10.1016/j.icesjms.2004.08.020.

Datta, S., Delius, G.W., and Law, R. 2010. A jump-growth model for predator--prey dynamics: derivation and application to marine ecosystems. Bull. Math. Biol. 72(6): 1361-1382.

Datta, S., Delius, G.W., Law, R., and Plank, M.J. 2011. A stability analysis of the power-law steady state of marine size spectra. J. Math. Biol. 63(4): 779-799.

Elton, C. 1927. Animal Ecology. In Animal ecology. doi: 10.1098/rstb.2010.0107.

Engelhard, G.H., Peck, M.A., Rindorf, A., Raab, K., Smout, S., Aarts, G., Deurs, M. Van, Brunel, T., Hoff, A., Lauerburg, R.A.M., Garthe, S., Andersen, K.H., Scott, F., Kooten, T. Van, Beare, D., and Peck, M.A. 2013. Marine Science.

Freedman, J.A., and Noakes, D.L.G. 2002. Why are there no really big bony fish? A point-of-view on maximum body size in teleosts and elasmobranchs. Rev. Fish Biol. Fish. 12: 403-416.

Froese, R., Walters, C., Pauly, D., Winker, H., Weyl, O.L.F., Demirel, N., Tsikliras, A.C., and Holt, S.J. 2015. A critique of the balanced harvesting approach to fishing. ICES J. Mar. Sci. doi: doi:10.1093/icesjms/fsv122.

Fulton, E.A., Link, J.S., Kaplan, I.C., Savina-Rolland, M., Johnson, P., Ainsworth, C., Horne, P., Gorton, R., Gamble, R.J., Smith, A.D.M., and Smith, D.C. 2011. Lessons in modelling and management of marine ecosystems: The Atlantis experience. Fish Fish. 12(2): 171-188. doi: 10.1111/j.1467-2979.2011.00412.x.

Fung, T., Farnsworth, K.D., Shephard, S., Reid, D.G., and Rossberg, A.G. 2013. Why the size structure of marine communities can require decades to recover from fishing. Mar. Ecol. Prog. Ser. 484: 155-171. doi: 10.3354/meps 10305.

Gilljam, D., Thierry, A., Edwards, F.K., Figueroa, D., Ibbotson, A.T., Jones, J.I., Lauridsen, R.B., Petchey, O.L., Woodward, G., and Ebenman, B. 2011. Seeing Double: Size-Based and Taxonomic Views of Food Web Structure. Adv. Ecol. Res. 45: 67-133. doi: 10.1016/B978-0-12-386475-8.00003-4.

Gislason, H., Daan, N., Rice, J.C., and Pope, J.G. 2010. Size, growth, temperature and the natural mortality of marine fish. Fish Fish. 11(2): 149-158. doi: 10.1111/j.1467-2979.2009.00350.x.

Haldane, J.B.S. 1928. On being the right size. In A treasury of science. Edited by H. Shapely, S. Raffort, and H. Wright. Harper, New York. pp. 321-325. 
704

705

706

707

708

709

710

711

712

713

714

715

716

717

718

719

720

721

722

723

724

725

726

727

728

729

730

731

732

733

734

735

736

737

738

739

Hall, S.J., Collie, J.S., Duplisea, D.E., Jennings, S., Bravington, M., and Link, J. 2006. A length-based multispecies model for evaluating community responses to fishing. Can. J. Fish. Aquat. Sci. 63(6): 1344-1359. doi: 10.1139/f06-039.

Hartvig, M. 2011. Ecological processes yield complex and realistic food webs. In Food Web Ecology. Lund University. pp. 73-100.

Hartvig, M., and Andersen, K.H. 2013. Coexistence of structured populations with size-based prey selection. Theor. Popul. Biol. 89: 24-33. doi: 10.1016/j.tpb.2013.07.003.

Hartvig, M., Andersen, K.H., and Beyer, J.E. 2011. Food web framework for sizestructured populations. J. Theor. Biol. 272(1): 113-122.

Houle, J.E., Andersen, K.H., Farnsworth, K.D., and Reid, D.G. 2013. Emerging asymmetric interactions between forage and predator fisheries impose management trade-offs. J. Fish Biol. 83(4): 890-904. doi: 10.1111/jfb.12163.

Houle, J.E., de Castro, F., Cronin, M.A., Farnsworth, K.D., Gosch, K.D., and Reid, D.G. 2015. Effects of seal predation on a modeled marine fish community and consequences for a commercial fishery. J. Appl. Ecol. doi: 10.1111/13652664.12548.

Houle, J.E., Farnsworth, K.D., Rossberg, A.G., and Dave, R. 2012. Assessing the sensitivity and specificity of fish community indicators to management action. Can. J. Fish. Aquat. Sci. 69(6): 1065-1079.

Jacobsen, N.S., Essington, T.E., and Andersen, K.H. 2015. Comparing model predictions for ecosystem based management. Can. J. Fish. Aquat. Sci. doi: 10.1139/cjfas-2014-0561.

Jacobsen, N.S., Gislason, H., and Andersen, K.H. 2014. The consequences of balanced harvesting of fish communities. Proc. R. Soc. B 281(1775): 20132701. doi: $10.1098 /$ rspb.2013.2701.

Jennings, S., and Collingridge, K. 2015. Predicting Consumer Biomass, SizeStructure, Production, Catch Potential, Responses to Fishing and Associated Uncertainties in the World's Marine Ecosystems. PLoS One 10(7): e0133794.

Jennings, S., Pinnegar, J.K., Polunin, N.V.C., and Boon, T.W. 2001. Weak crossspecies relationships between body size and trophic level belie powerful sizebased trophic structuring in fish communities. J. Anim. Ecol. 70(6): 934-944.

Kleiber, M. 1932. Body size and metabolism. Hilgardia 6: 315-353.

Kolding, J., Jacobsen, N.S., Andersen, K.H., and van Zwieten, P. 2015. Maximizing fisheries yields while maintaining community structure. Can. J. Fish. Aquat. Sci.

Law, R., Plank, M.J., James, A., and Blanchard, J.L. 2009. Size-spectra dynamics 
from stochastic predation and growth of individuals. Ecology 90(3): 802-11.

741

742

743

744

745

746

747

748

749

750

751

752

753

754

755

756

757

758

759

760

761

762

763

764

765

766

767

768

769

770

771

772

773

774

775

Law, R., Plank, M.J., and Kolding, J. 2014. Balanced exploitation and coexistence of interacting, size-structured, fish species. Fish Fish. doi: 10.1111/faf.12098.

Lefort, S., Aumont, O., Bopp, L., Arsouze, T., Gehlen, M., and Maury, O. 2014. Spatial and body-size dependent response of marine pelagic communities to projected global climate change. Glob. Chang. Biol. doi: 10.1111/gcb.12679.

Lewy, P., and Vinther, M. 2004. A stochastic age-length-structured multispecies model applied to North Sea stocks. ICES (CM/FF:20): 33 pp.

Maury, O., Faugeras, B., Shin, Y.J., Poggiale, J.C., Ari, T.B., and Marsac, F. 2007a. Modeling environmental effects on the size-structured energy flow through marine ecosystems. Part 1: The model. Prog. Oceanogr. 74(4): 479-499.

Maury, O., and Poggiale, J. 2013. From individuals to populations to communities: A dynamic energy budget model of marine ecosystem size-spectrum including life history diversity. J. Theor. Biol.: 1-20. doi: 10.1016/j.jtbi.2013.01.018.

Maury, O., Shin, Y.J., Faugeras, B., Ben Ari, T., and Marsac, F. 2007b. Modeling environmental effects on the size-structured energy flow through marine ecosystems. Part 2: Simulations. Prog. Oceanogr. 74(4): 500-514.

Neuheimer, A.B., Hartvig, M., Heuschele, J., Hylander, S., Kiørboe, T., Olsson, K., Sainmont, J., and Andersen, K.H. 2015. Adult and offspring size in the ocean over 17 orders of magnitude follows two life-history strategies. Ecology.

Persson, L., van Leeuwen, A., and de Roos, A.M. 2014. The ecological foundation for ecosystem-based management of fisheries: mechanistic linkages between the individual-, population-, and community-level dynamics. ICES J. Mar. Sci. 71(8): 2268-2280. doi: 10.1093/icesjms/fst231.

Peters, R.H. 1983. The ecological implications of body size. Cambridge University Press.

Pikitch, E.K., Santora, C., Babcock, E.A., Bakun, A., Bonfil, R., Conover, D.O., Dayton, P., Doukakis, P., Fluharty, D., Heneman, B., and others. 2004. Ecosystem-based fishery management. Science 305(5682): 346-347.

Plagányi, É.E. 2007. Models for an ecosystem approach to fisheries. FAO Fish. Tech. Pap. (477): 108 p.

Pope, J.G., Falk-Pedersen, J., Jennings, S., Rice, J.C., Gislason, H., and Daan, N. 2009. Honey, I cooled the cods: Modelling the effect of temperature on the structure of Boreal/Arctic fish ecosystems. Deep Sea Res. Part II 56(21-22): 2097-2107. doi: 10.1016/j.dsr2.2008.11.021.

Pope, J.G., Rice, J.C., Daan, N., Jennings, S., and Gislason, H. 2006. Modelling an 
776

777

778

779

780

781

782

783

784

785

786

787

788

789

790

791

792

793

794

795

796

797

798

799

800

801

802

803

804

805

806

807

808

809

810

811

812

exploited marine fish community with 15 parameters-results from a simple sizebased model. ICES J. Mar. Sci. 63(6): 1029-1044.

Rall, B.C., Brose, U., Hartvig, M., Kalinkat, G., Schwarzmüller, F., Vucic-Pestic, O., and Petchey, O.L. 2012. Universal temperature and body-mass scaling of feeding rates. Philos. Trans. R. Soc. B Biol. Sci. 367: 2923-2934. doi: 10.1098/rstb.2012.0242.

Reuman, D.C., Gislason, H., Barnes, C., Mélin, F., and Jennings, S. 2014. The marine diversity spectrum. J. Anim. Ecol. 83(4): 963-979. doi: 10.1111/13652656.12194.

Rice, J., and Gislason, H. 1996. Patterns of change in the size spectra of numbers and diversity of the North Sea fish assemblages, as reflected in surveys and models. ICES J. Mar. Sci. 53: 1214-1225.

Rijnsdorp, A., and Leeuwen, P. Van. 1992. Density-dependent and independent changes in somatic growth of female North Sea plaice Pleuronectes platessa between 1930 and 1985 as revealed by back-calculation of otoliths. Mar. Ecol. Prog. Ser. 88: 19-32.

Rochet, M.-J., and Benoît, E. 2012. Fishing destabilizes the biomass flow in the marine size spectrum. Proc. Biol. Sci. 279(1727): 284-92. doi: 10.1098/rspb.2011.0893.

Rochet, M.J., Collie, J.S., Jennings, S., and Hall, S.J. 2011. Does selective fishing conserve community biodiversity? Predictions from a length-based multispecies model. Can. J. Fish. Aquat. Sci. 68(3): 469-486.

de Roos, A.M., and Persson, L. 2001. Physiologically structured models - from versatile technique to ecological theory. Oikos 94: 51-71.

De Roos, A.M., and Persson, L. 2002. Size-dependent life-history traits promote catastrophic collapses of top predators. Proc. Natl. Acad. Sci. U.S.A. 99(20): $12907-12912$.

de Roos, A.M., Schellekens, T., van Kooten, T., van de Wolfshaar, K., Claessen, D., and Persson, L. 2008. Simplifying a physiologically structured population model to a stage-structured biomass model. Theor. Popul. Biol. 73(1): 47-62. doi: 10.1016/j.tpb.2007.09.004.

Rossberg, A.G. 2012. A complete analytic theory for structure and dynamics of populations and communities spanning wide ranges in body size. Adv. Ecol. Res. 46: 429-522.

Rossberg, A.G. 2013. Food Webs and Biodiversity: Foundations, Models, Data. Wiley.

Rossberg, A.G., and Farnsworth, K.D. 2011. Simplification of structured population 

dynamics in complex ecological communities. Theor. Ecol. 4: 449-465. doi: 10.1007/s12080-010-0088-7.

Rossberg, A.G., Houle, J.E., and Hyder, K. 2013. Stock-recruitment relations controlled by feeding interactions alone. Can. J. Fish. Aquat. Sci. 70: 14471455. doi: 10.1139/cjfas-2012-0531.

Scott, F., Blanchard, J.L., and Andersen, K.H. 2014. mizer: an R package for multispecies, trait-based and community size spectrum ecological modelling. Methods Ecol. Evol. doi: 10.1111/2041-210X.12256.

Sheldon, R., and Prakash, A. 1972. The size distribution of particles in the ocean. Limnol. Oceanogr. XVII(May): 327-340.

Sheldon, R.W., and Parsons, T.R. 1967. A continuous size spectrum for particulate matter in the sea. J. Fish. Res. Board. Canada. 24(5): 909-915.

Sheldon, R.W., Sutcliffe Jr., W.H., and Paranjape, M.A. 1977. Structure of pelagic food chain and relationship between plankton and fish production. J. Fish. Res. Board Canada 34: 2344-2353.

Silvert, W., and Platt, T. 1978. Energy flux in the pelagic ecosystem: a timedependent equation. Limnol. Oceanogr. 23(4): 813-816.

Spence, M.A., Blackwell, P.G., and Blanchard, J.L. 2015. Parameter uncertainty of a dynamic multi-species size spectrum model. Can. J. Fish. Aquat. Sci.

Sprules, W.G., and Barth, L.E. (n.d.). Surfing the biomass size spectrum: some remarks on history, theory, and application. Can. J. Fish. Aquat. Sci.: this issue.

Thorpe, R.B., Le Quesne, W.J.F., Luxford, F., Collie, J.S., and Jennings, S. 2015. Evaluation and management implications of uncertainty in a multispecies sizestructured model of population and community responses to fishing. Methods Ecol. Evol. 6(1): 49-58. doi: 10.1111/2041-210X.12292.

Ursin, E. 1973. On the prey size preferences of cod and dab. Meddelelser fra Danmarks Fisk. og Havundersøgelser 7: 85-98.

Werner, E.E., and Gilliam, J.F. 1984. The ontogenetic niche and species interactions in size-structured populations. Ann. Rev. Ecol. Syst. 15: 393-425.

West, G.B., Brown, J.H., and Enquist, B.J. 2001. A general model for ontogenetic growth. Nature 413: 628-631.

Winberg, G.G. 1956. Rate of metabolism and food requirements of fishes. J. Fish. Res. Board Canada 194: 1-253.

Woodworth-Jefcoats, P., Polovina, J., Howell, E., and Blanchard, J. 2015. Two takes on the ecosystem impacts of climate change and fishing: comparing a size-based and a species-based ecosystem model in the central North Pacific. Prog. 

Oceanogr. doi: 10.1016/j.pocean.2015.04.004.

Woodworth-Jefcoats, P.A., Polovina, J.J., Dunne, J.P., and Blanchard, J.L. 2013. Ecosystem size structure response to 21 st century climate projection: Large fish abundance decreases in the central North Pacific and increases in the California Current. Glob. Chang. Biol. 19(3): 724-733. doi: 10.1111/gcb.12076.

Worm, B., Hilborn, R., Baum, J.K., Branch, T.A., Collie, J.S., Costello, C., Fogarty, M.J., Fulton, E.A., Hutchings, J.A., Jennings, S., Jensen, O.P., Lotze, H.K., Mace, P.M., McClanahan, T.R., Minto, C., Palumbi, S.R., Parma, A.M., Ricard, D., Rosenberg, A.A., Watson, R., and Zeller, D. 2009. Rebuilding global fisheries. Science 325(5940): 578-85. doi: 10.1126/science.1173146.

Zhang, C., Chen, Y., and Ren, Y. 2015. Assessing uncertainty of a multispecies sizespectrum model resulting from process and observation errors. ICES J. Mar. Sci. doi: doi:10.1093/icesjms/fsv086.

Zhang, L., Hartvig, M., Knudsen, K., and Andersen, K.H. 2013. Size-based predictions of food web patterns. Theor. Ecol. 7(1): 23-33.

Zhang, L., Thygesen, U.H., Knudsen, K., and Andersen, K.H. 2012. Trait diversity promotes stability of community dynamics. Theor. Ecol. 6(1): 57-69. doi: 10.1007/s12080-012-0160-6.

Zijlema, M. 1996. On the construction of a third-order accurate monotone convection scheme with application to turbulent flows in general domains. Int. J. Numer. 
Encounter and consumption

Prey size selection

$$
\phi\left(\frac{w_{\text {prey }}}{w}\right)=\exp \left[-\left(\ln \left(\frac{\beta_{i} w_{\text {prey }}}{w}\right)\right)^{2} /\left(2 \sigma_{i}^{2}\right)\right]
$$

Clearance rate

$$
V_{i}(w)=\gamma_{i} w^{q} \text { with } \gamma_{i}=\frac{f_{0} h_{i} \beta_{i}^{n-q}}{\left(1-f_{0}\right) \sqrt{2 \pi} \kappa_{r} \sigma_{i}}
$$

Encountered food

$$
E_{i}(w)=V_{i}(w) \sum_{j} \theta_{i j} \int_{0}^{\infty} \phi\left(\frac{w_{\text {prey }}}{w}\right) N_{j}\left(w_{\text {prey }}\right) w_{\text {prey }} \mathrm{d} w_{\text {prey }}
$$

Maximum consumption

$$
I_{\max . i}(w)=h_{i} w^{n}
$$

rate

Feeding level

$$
f_{i}(w)=\frac{E_{i}(w)}{E_{i}(w)+I_{\max . i}(w)}
$$

Growth and reproduction

Maturation function

$$
\psi(w)=\left[1+\left(\frac{w}{\eta_{i} W_{i}}\right)^{-10}\right]^{-1}\left(\frac{w}{W_{i}}\right)^{1-n}
$$

Somatic growth

$$
\begin{aligned}
g_{i}(w) & =\left(\alpha f_{i}(w) I_{\max . i}-k_{i} w^{p}\right)(1-\psi(w)) \\
g(w) & =\bar{\epsilon}\left(\alpha f(w) I_{\max }-k w^{p}\right)(1-\psi(w))
\end{aligned}
$$

Egg production

$$
\begin{aligned}
& g_{r}(w)=\left(\alpha f_{i}(w) I_{\max . i}-k_{i} w^{p}\right) \psi(w) \\
& g_{r}(w)=\bar{\epsilon}\left(\alpha f(w) I_{\max }-k w^{p}\right) \psi(w)
\end{aligned}
$$

Boundary condition

Population egg

production

$$
R_{\mathrm{p} . i}=\frac{\varepsilon}{2 w_{0}} \int_{w_{0}}^{W_{i}} N_{i}(w) g_{r}(w) \mathrm{d} w
$$

Recruitment

$$
R_{i}=R_{\max . i} \frac{R_{\mathrm{p} . i}}{R_{\max . i}+R_{\mathrm{p} . i}}
$$

Boundary condition

$$
N_{i}\left(w_{0}\right) g\left(w_{0}\right)=R_{i}
$$


Mortality

Background mortality

$$
\mu_{0}=Z_{0} W_{i}^{Z}
$$

Predation mortality $\quad \mu_{\mathrm{p} . i}\left(w_{\text {prey }}\right)=\sum_{j} \int_{w_{0}}^{W_{j}} \phi\left(\frac{w_{\text {prey }}}{w}\right)\left(1-f_{j}(w)\right) V_{j}(w) \theta_{i j} N_{j}(w) \mathrm{d} w^{\text {M13 }}$

Resource spectrum

Population dynamics

$$
\frac{\mathrm{d} N_{\mathrm{r}}(w)}{\mathrm{d} t}=r_{0} w^{n-1}\left(\kappa(w)-N_{\mathrm{r}}(w)\right)-\mu_{\mathrm{p} . r}(w) N_{r}(w)
$$

Carrying capacity

$$
\kappa(w)=\kappa_{\mathrm{r}} w^{-\lambda}
$$

Trait-based model

Maximum

$$
R_{\text {max. } i}=\kappa_{R} \kappa\left(\alpha f_{0} h w_{0}^{n}-k_{s} w_{0}^{p}\right) W_{i}^{2 n-q-3+a} w_{0}^{-n-a} \Delta W_{i}
$$

recruitment

Physiological mortality

$$
a=\frac{f_{0} h}{\alpha f_{0} h-k_{s}} \beta^{2 n-q-1} \exp \left[\frac{\left(2 n(q-1)-q^{2}+1\right) \sigma^{2}}{2}\right]
$$

875

876

877 
Symbol Explanation

\begin{tabular}{|c|c|c|}
\hline$w$ & Body weight & $\mathrm{g}$ \\
\hline$W$ & Asymptotic body weight & g \\
\hline$N(w)$ & Abundance density spectrum & numbers/gram b \\
\hline$\beta$ & Preferred predator-prey mass ratio & $100^{c}$ \\
\hline$\sigma$ & Width of size preference & $1.3 \mathrm{~d}$ \\
\hline$\theta$ & Species preference & 1 \\
\hline$q$ & Exponent for clearance rate & 0.8 e \\
\hline$f_{0}$ & Initial feeding level & $0.6^{\mathrm{f}}$ \\
\hline$\alpha$ & Assimilation efficiency & 0.6 \\
\hline$h$ & Factor for maximum consumption & $20 \mathrm{~g}^{0.25} \mathrm{yr}^{-1} \mathrm{~g}$ \\
\hline$n$ & Exponent for maximum consumption & $3 / 4 \mathrm{~h}$ \\
\hline$k_{s}$ & Factor for standard metabolism & $2.4 \mathrm{~g}^{0.25} \mathrm{yr}^{-1}$ \\
\hline$p$ & Exponent for standard metabolism & $3 / 4 \mathrm{~h}$ \\
\hline$\eta$ & Ratio between size at maturation and $W$ & $0.25(0.01) \mathrm{i}$ \\
\hline$\kappa_{R}$ & Constant for max. recruitment & $1.7 \mathrm{~g}$ \\
\hline$\varepsilon$ & Efficiency of reproduction & $0.1 \mathrm{j}$ \\
\hline$w_{0}$ & Egg size & $1 \mathrm{mg} \mathrm{k}$ \\
\hline$Z_{0}$ & Factor for background mortality & $2 \mathrm{~g}^{0.25 \mathrm{yr}^{-1} \quad \mathrm{l}}$ \\
\hline$z$ & Exponent for background mortality & $-0.25 \mathrm{~m}$ \\
\hline$r_{0}$ & Resource productivity & $4 \mathrm{~g}^{0.25} \mathrm{yr}^{-1} \mathrm{n}$ \\
\hline$w_{\text {cut }}$ & Maximum size of resource & $1 \mathrm{~g}$ o \\
\hline$\kappa_{r}$ & Resource carrying capacity & $10^{12} \mathrm{~g}^{-1} \mathrm{~b}, \mathrm{~g}$ \\
\hline
\end{tabular}

Value and unita

(1)


aValues in parentheses refers to the community model

bThe units of the abundance density spectrum could also be expressed as a concentration, i.e., as numbers/gram/volume or numbers/gram/area. In that case the units of the resource carrying capacity should also be changed accordingly. Further, the units of the clearance rate would become volume per time or area per time respectively.

c Ursin 1973; Jennings et al. 2001.

d Ursin (1973) finds $\sigma=1$, but here $\sigma$ is increased to represent cross-species variation. In the food-web model $\sigma=1$ except if specific knowledge about a species exists.

e Andersen and Beyer, 2006.

$\mathrm{f}$ Assumes that fish in general are not satiated $\left(f_{0}<1\right)$ while also have a signifant surplus after assimilation and standard metabolism, i.e, larger than $k_{s} /(\alpha h)=0.2$. Setting $f_{0}$ in the middle of the range $0.2 \ldots 1$ gives 0.6. See also Hartvig et al. (2011), App. E.

g Adjusted to give similar results to the North Sea model (Blanchard et al. 2014), despite the use of different exponent for $n$; see text and Figure 2.

h See text.

i Beverton, 1992.

j Andersen and Beyer (2013). Note that this differs from the North Sea model (Blanchard et al. 2014), where a value of $\varepsilon=1$ was used. This will (in the North Sea model) lead to overestimations of $F_{\text {msy }}$ for individual species.

k Neuheimer et al., 2015.

l This value leads to a background mortality on a $10 \mathrm{~kg}$ individual of $0.2 \mathrm{yr}^{-1}$. These individuals will have little predation mortality in the model, so background mortality is the largest part. See also discussion.

m Standard "metabolic" assumption (Brown et al. 2004).

n Hartvig et al., 2011.

o Set to include mesoplankton, such as shrimps.

881

882 
884 Table 3 Implementations of size spectrum models. References are given to where a particular 885 model was first formulated or calibrated to specific system, but not to applications of the models.

886 The column "growth" refers to the functional response used to calculate growth rate.

\begin{tabular}{|c|c|c|c|c|}
\hline Reference & Growth & Reproduction & Resource & Density dependence \\
\hline \multicolumn{5}{|l|}{ Food-web models } \\
\hline Hall et al. 2006, & Fixed & Fixed & N.a. & Stock-recruitment \\
\hline \multicolumn{5}{|l|}{ Rochet et al. 2011} \\
\hline Hartvig 2011, Hartvig & Type II & Dynamic & Dynamic & Emergent \\
\hline \multicolumn{5}{|l|}{ et al. 2011} \\
\hline Houle et al. 2012, & Type II & Dynamic & Dynamic & Stock-recruitment \\
\hline \multicolumn{5}{|l|}{ Blanchard et al. 2014} \\
\hline Rossberg et al. 2013 & Type II & Dynamic & Dynamic & Emergent \\
\hline \multicolumn{5}{|l|}{ Trait-based models } \\
\hline Pope et al. 2006, 2009 & Fixed & Fixed & N.a. & Stock-recruitment \\
\hline Andersen and & Type II & Fixed & Dynamic & Fixed recruitment \\
\hline \multicolumn{5}{|l|}{ Pedersen 2010} \\
\hline Houle et al. 2013; & Type II & Dynamic & Dynamic & Stock-recruitment \\
\hline Jacobsen et al. 2014 & & & & relationship \\
\hline Maury and Poggiale & Type II & Dynamic & Dynamic & Switching \\
\hline \multicolumn{5}{|l|}{2013} \\
\hline \multicolumn{5}{|l|}{ Community models } \\
\hline Benoît and Rochet & Type I & N.a. & Fixed & Fixed boundary \\
\hline 2004; Blanchard et al. & & & & condition \\
\hline \multicolumn{5}{|l|}{ 2009; Law et al. 2009} \\
\hline (1) & & & & \\
\hline Blanchard et al. 2011 & Type I \& & Dynamic & Fixed & Fixed boundary \\
\hline
\end{tabular}


condition

Maury et al. $2007 \quad$ Type II Dynamic Dynamic

$\begin{array}{llll}\text { This article } & \text { Type II N.a. Dynamic Fixed boundary }\end{array}$

condition

887

888 (1) Note that Law et al. (2009) uses a slightly different conservation equation than the 889 other models.

890 


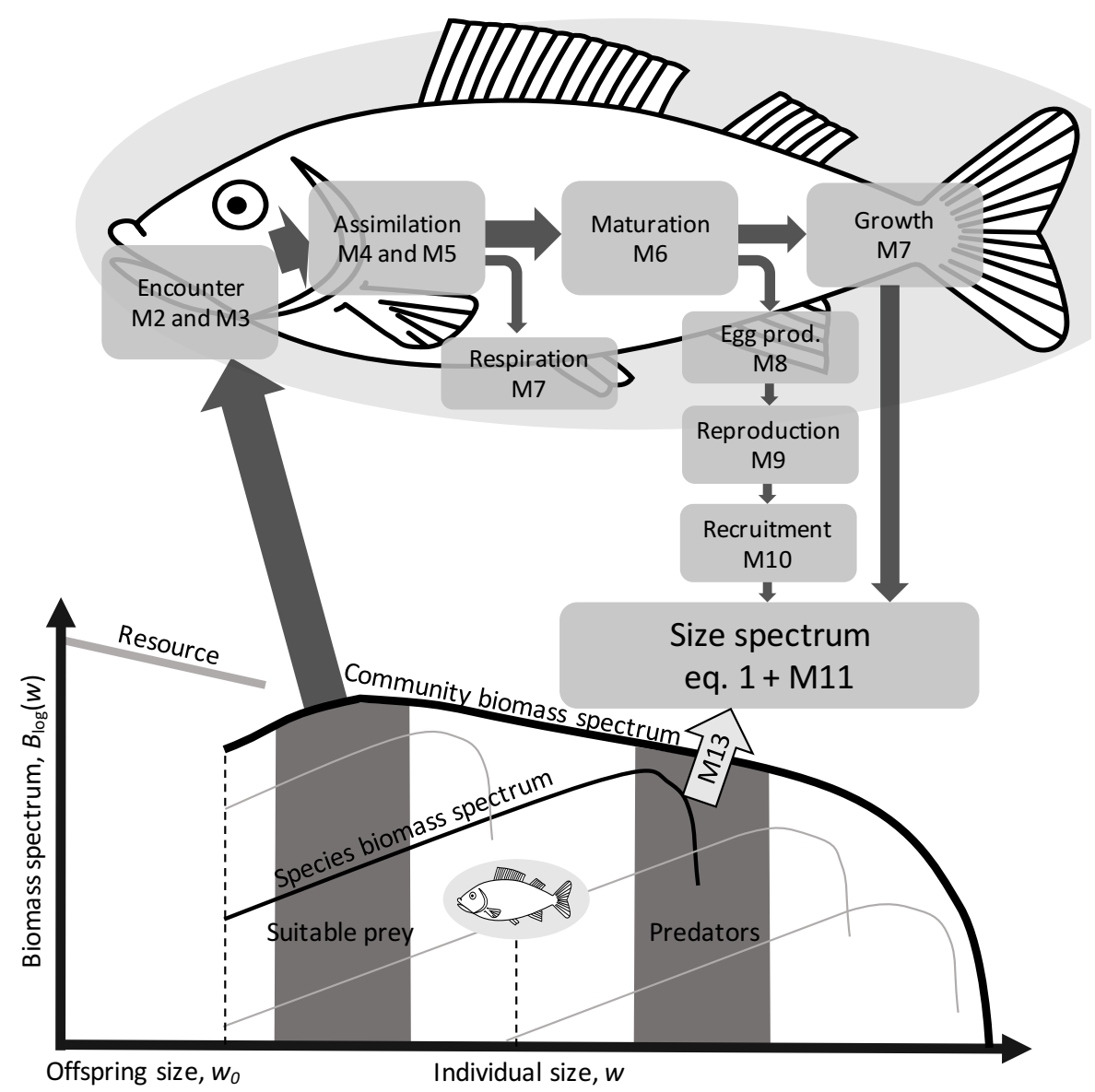

893 Figure 1. Illustration of the size spectrum calculation of for a species (thin black line) from the perspective of

894 an individual at a given size. All processes inside the oval around the fish are individual level processes, with

895 dark grey arrows representing mass flows and the light grey arrow representing mortality losses. The scaling from individual level processes of growth, egg production and predation are facilitated by the McKendric-von Foerster equation (eq. 1) and the boundary condition (M11). The process is iterative with the size spectrum

898 being needed to calculate the population-level measures of reproduction and recruitment. The numbers refer to the equations in Table 1. 

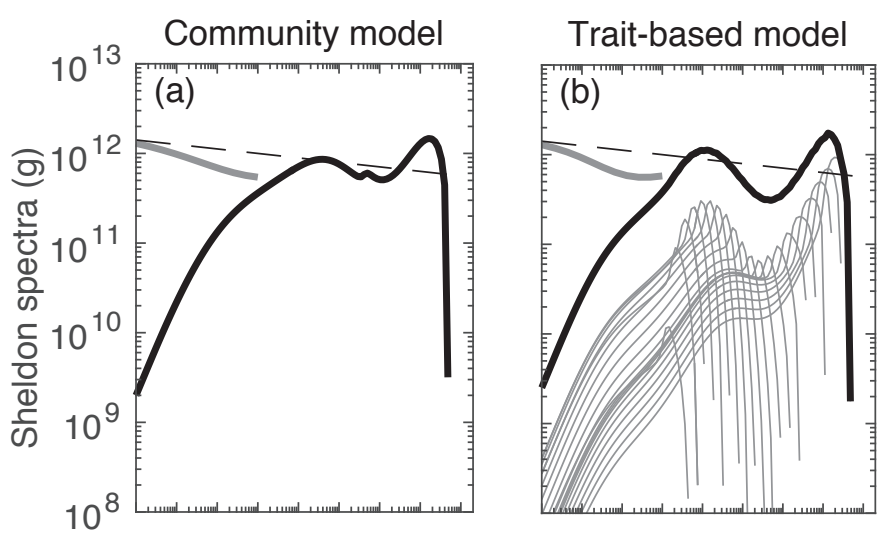

Food-web model
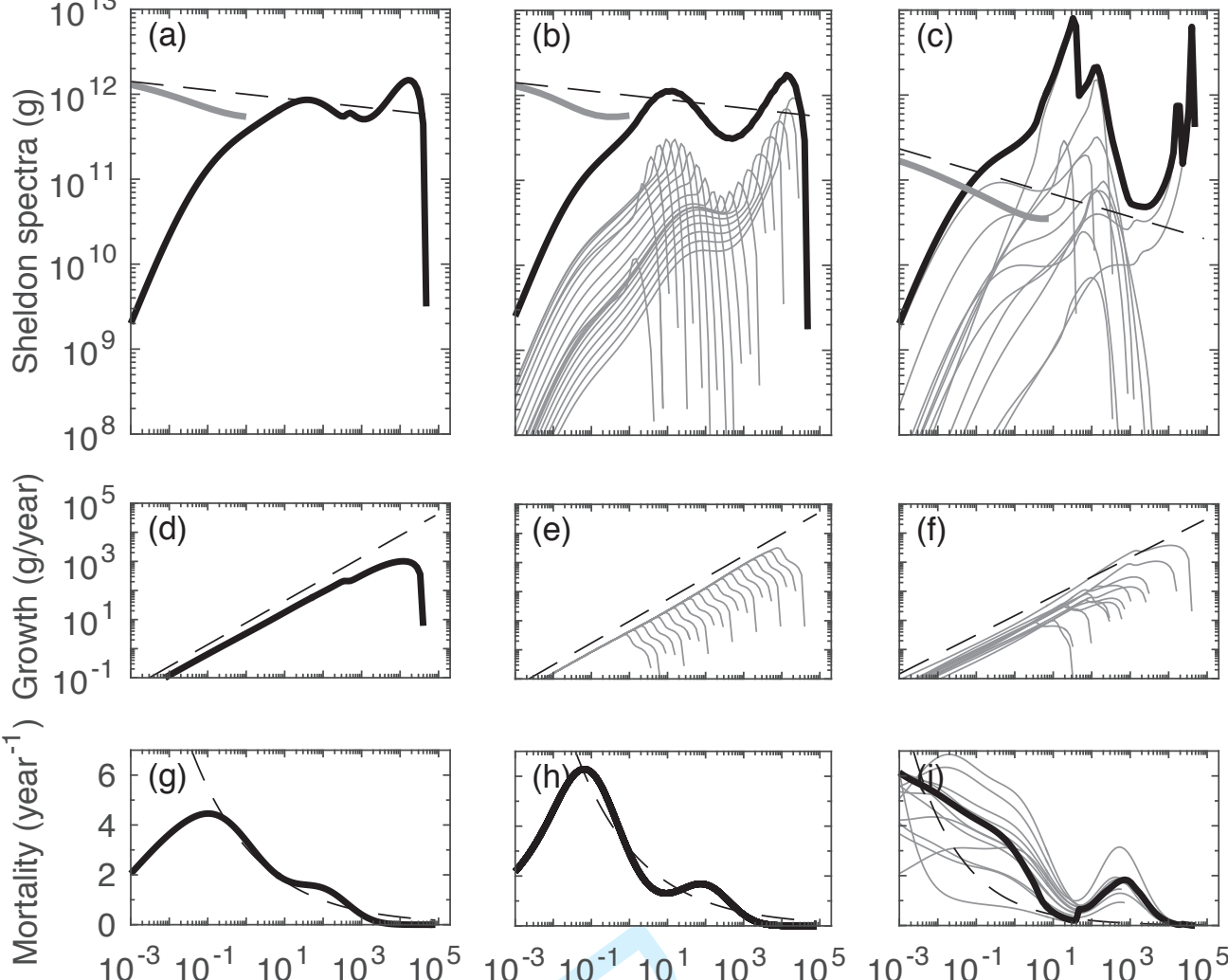

900

901

Figure 2. Solutions of the community model (left column), the trait-based model (middle column), the North

902

Sea food-web model (right column) and the equilibrium solution (dashed lines) in an un-fished situation as a

903

function of body mass. Top: Biomass size spectra in the "Sheldon scaling" depicting biomass in log-spaced size

904 groups, showing community spectrum (thick), background spectrum (thick grey), species spectra (thin grey)

905 and the theoretic average spectrum from the equilibrium solution (dashed). Middle: growth rates (solid)

906 compared to the maximum possible growth rate when fed ad libitum (dashed; for the food-web model this is an

907 average over all species). Bottom: average predation mortality, (solid), for each species (grey) and from the equilibrium solution (dashed). Note that in the trait-based model all asymptotic size classes experience the same predation mortality since feeding is only based on size. 

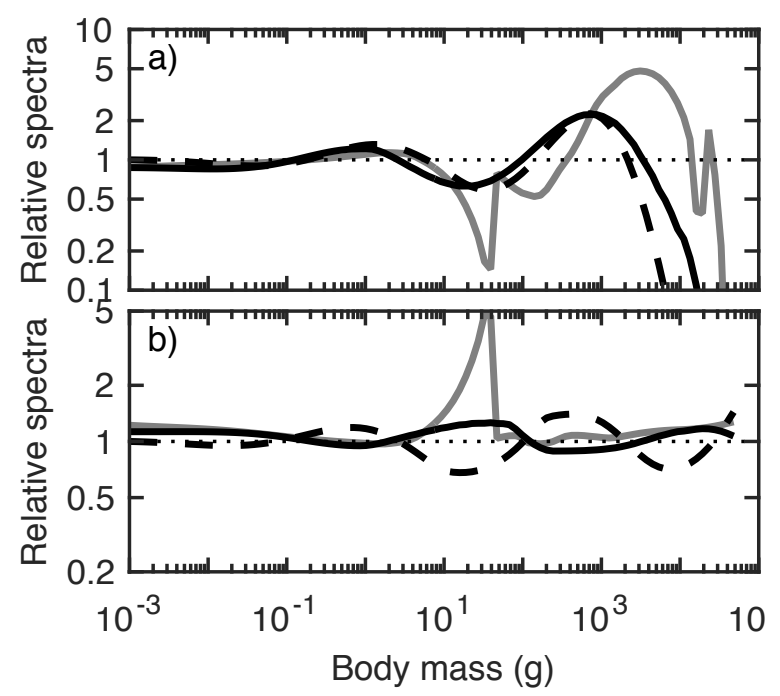

913 Figure 3. Response to fishing on the community for the North Sea food-web model (grey), the trait-based model

914 (solid black) and the community model (dashed black). Size spectra are shown relative to the unfished size

915 spectra from Figure 2. a) Response to fishing all species with a trawl-type selectivity pattern. Selection on each

916 species starts at $0.05 \mathrm{~W}$ and the fishing mortality is $0.5 \mathrm{yr}^{-1}$. In the community model all individuals larger than

$91710 \mathrm{~g}$ are fished. b) Changes to the fished community in panel a) when forage fishing is removed, i.e. fishing on

918 species with an asymptotic size smaller than $200 \mathrm{~g}$ (or individuals smaller than $200 \mathrm{~g}$ for the community

919 model). 

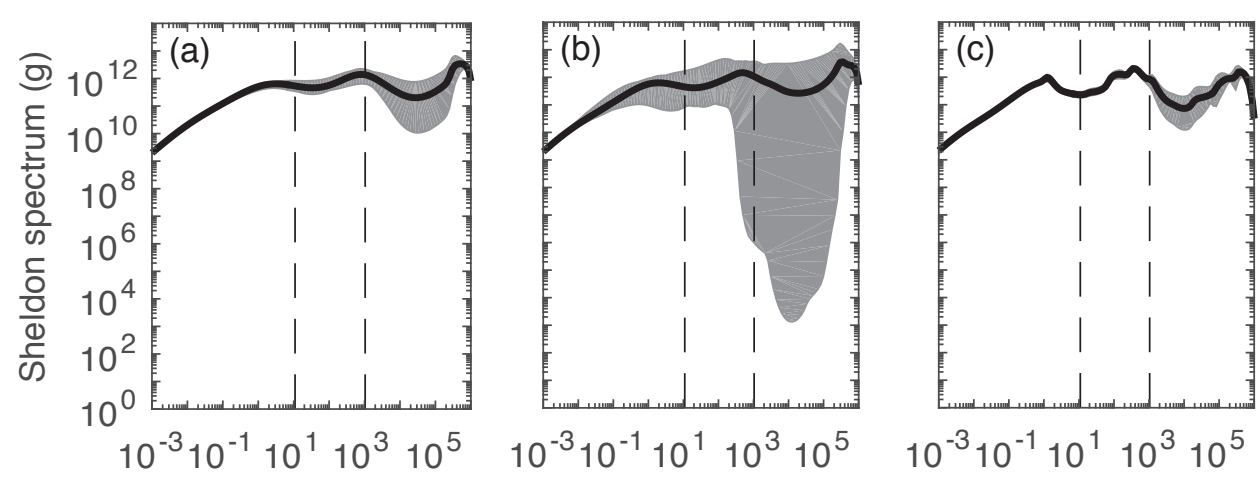

Body mass (g)
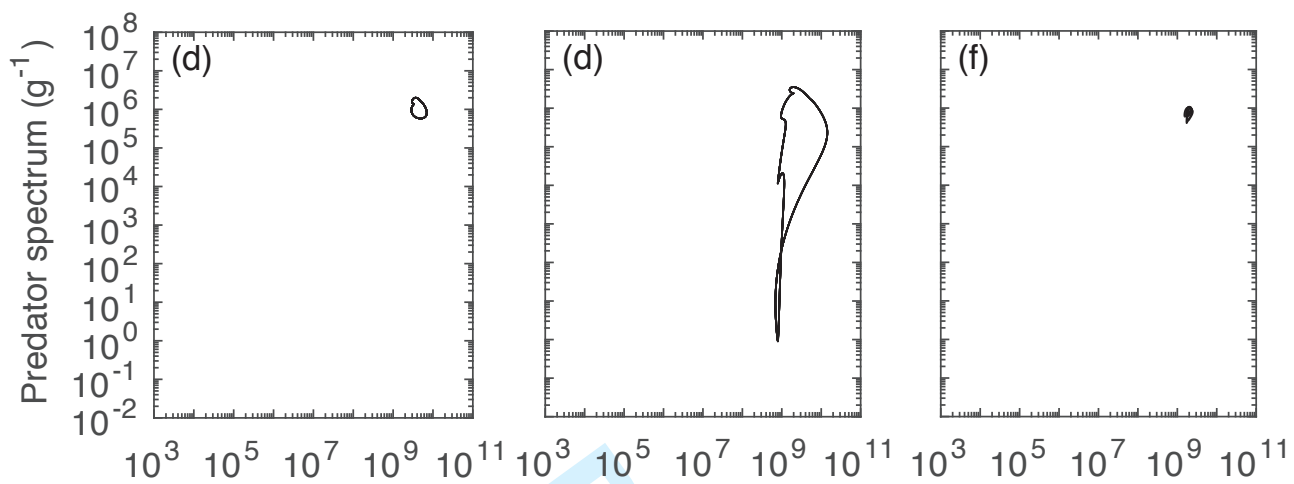

921 Prey spectrum $\left(\mathrm{g}^{-1}\right)$

922 Figure 4. Illustration of the time-dependent solution in the community model (two left-most columns) and the

923 trait-based model (right-most column). Top row: average biomass spectra (solid) and range of variation (grey

924 patch). Bottom row: the phase-plane between a prey of $10 \mathrm{~g}$ and a predator with a size one predator-prey mass

925 larger $(\beta 10 \mathrm{~g})$ illustrated with vertical dashed lines in the top row. Left column: community model with width

926 of size preference $\sigma=1.3$. Middle column: community model with $\sigma=1$. Right column: trait-based model with $\sigma=1$. Other parameters as in Figs. 2 and 3, except that the largest size of the organisms is $1000 \mathrm{~kg}$. 


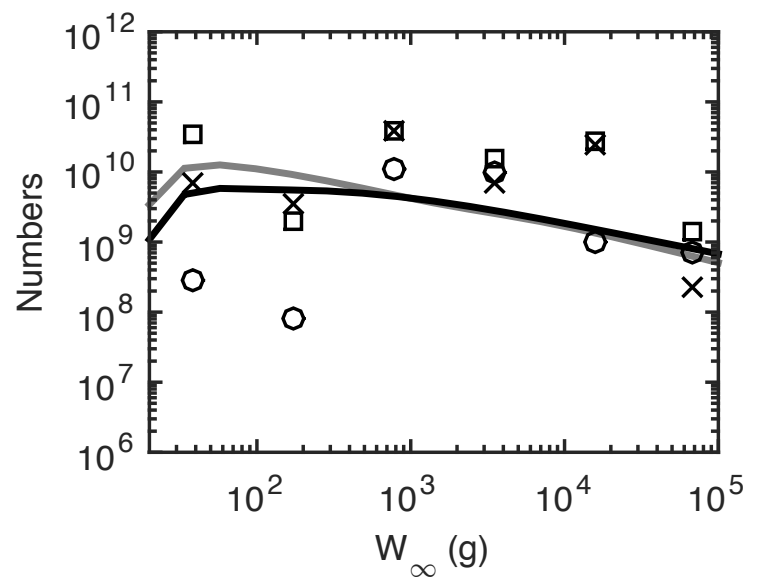

930 Figure 5. Asymptotic weight spectrum (extended Sheldon hypothesis), showing total numbers of individuals in

931 logarithmically spaced asymptotic weight groups in an unfished (grey) and fished situation (black) from the

932 trait-based model. The simulation results are compared to data from three different trawl surveys (Daan et al.

933 2005). It is assumed that the trawl surveys only retain individuals larger than $10 \mathrm{~cm}$.

934

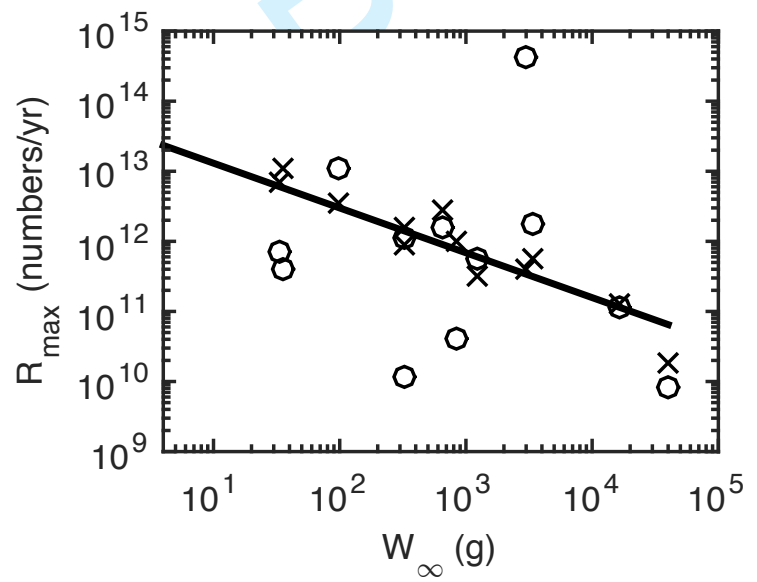

936 Figure 6. Maximum recruitment, $R_{\text {max }}$, for the North Sea model (circles) and the trait-based model with log-

937 spaces asymptotic size groups (line) and with asymptotic size groups with the same asymptotic sizes as in the $938 \quad$ North Sea model (crosses). 


\section{Appendices for: The theoretical foundations for size spectrum models of fish communities}

\section{Appendix A: derivations of equilibrium solutions}

The predation mortality can be derived from the community spectrum (eq. 3) (Andersen and Beyer 2006):

$$
\mu_{p}=a A w^{n-1},
$$

where $A=\alpha f_{0} h-k_{s}$ and $a$ is the physiological mortality (M16). Mortality scales with exponent $n-$ $1 \approx-0.25$ in accordance with empirical observations (McGurk 1986).

\section{Maximum recruitment}

The maximum recruitment in the trait-based model is calculated using the equilibrium solution $N\left(w_{0}\right)$ from (eq. 2). This solution provides a prediction for the relative abundance of species depending on their asymptotic size. The recruitment needed to support this abundance of individuals at size $w_{0}$ is given by the boundary condition (M11):

$$
R_{\max . i}=\kappa_{R} g\left(w_{0}\right) N\left(w_{0}, W_{i}\right) \Delta W_{i}
$$

where $\Delta W_{i}=\sqrt{W_{i} / W_{i-1}}$ is the spacing between asymptotic size groups, which is needed to come from the joint size and asymptotic size distribution in (1) to the size distribution (without asymptotic size) needed for the boundary condition. Inserting expressions for growth and abundance at size $w_{0}$ and assuming that $w_{0} \ll W$ leads to the approximation in (M16). The dimensionless constant $\kappa_{R}$ determines the strength of early-life density dependent regulation imposed by the stockrecruitment relationship by setting the ratio between $R_{\max }$ and $\kappa$ This free parameter effectively determines the ratio between piscivory and planktivory among the smallest fish: a higher value of $\kappa_{R}$ 
leads to a more abundant fish spectrum compared to the resource spectrum, and thus a higher the level of piscivory (Houle et al. 2013). For the simulations presented here, $\kappa_{R}$ has been manually regulated to ensure that the predation mortality of $1 \mathrm{~g}$ individuals is on the order of 3 year $^{-1}$ (Figure 2). If $\kappa_{R}$ is very large, piscivorous mortality is high and early-life density dependent regulation is small, leading to competitive exclusion between the species groups until only two species are left, a small and a large species (Hartvig and Andersen 2013).

\section{Average growth efficiency}

For an individual at the asymptotic size the growth rate is zero and the growth efficiency is zero, while a juvenile uses all available energy for growth. The average growth efficiency used in the community model represents the distribution of growth efficiencies between individuals with the same size (Andersen et al. 2009). It can be calculated simply from the conservation equation at steady state:

$$
\frac{\mathrm{d} g N_{c}}{\mathrm{~d} w}=-\mu_{p} N_{c}
$$

Inserting the description of growth in the community models as $g(w)=\bar{\alpha} A w^{n}$ and the mortality from (A1) gives the average growth efficiency:

$$
\bar{\alpha}=\frac{a}{2+q-2 n} \approx 0.51
$$

The entire distribution of the growth efficiency is derived in Zhang et al. (2012). 


\section{Appendix B: numerical solution procedure}

The solution is discretized on a logarithmic grid starting with the first grid point $w_{1}$ set to the egg size $w_{0}$, and the following grid points as $w_{j}=C w_{j-1}$, for $j>1$. The "expansion factor" $C>1$

determines the number of grid points. For each species $i$, the growth and mortality are calculated using the previous time-step's solution, $g_{i . j}^{t}$ and $\mu_{i . j}^{t}$, with $t$ being the time step, at all grid points $j$.

The discretization scheme is first-order implicit for the time derivative and first-order upwind for the mass-derivative:

$$
\frac{N_{i . j}^{t+1}-N_{i . j}^{t}}{\Delta t}+\frac{g_{i . j}^{t} N_{i . j}^{t+1}-g_{i . j-1}^{t} N_{i . j-1}^{t+1}}{\Delta w_{j}}=-\mu_{i . j}^{t} N_{i . j}^{t+1}
$$

with $\Delta w_{j}=w_{j}-w_{j-1}$. This may be rewritten by collecting terms of $N$ :

$$
N_{i . j-1}^{t+1}\left(-\frac{\Delta t}{\Delta w_{j}} g_{i . j-1}^{t}\right)+N_{i . j}^{t+1}\left(1+\frac{\Delta t}{\Delta w_{j}} g_{i . j}^{t}+\mu_{i . j}^{t}\right)=N_{i . j}^{t}
$$

which by naming the terms in the two parentheses $A_{i . j}$ and $B_{i . j}$ becomes:

$$
N_{i . j-1}^{t+1} A_{i . j}+N_{i . j}^{t+1} B_{i . j}=N_{i . j}^{t}
$$

This may rewritten as an explicit expression for $N_{i . j}^{t+1}$ :

$$
N_{i . j}^{t+1}=\frac{N_{i . j}^{t}-A_{i . j} N_{i . j-1}^{t+1}}{B_{i . j}}
$$


which can be solved as an iteration once the spectrum in the first grid cell, $N_{i .1}^{t+1}$, is known. This found using the boundary condition eq. (2) to give

$$
N_{i .1}^{t+1}=N_{i .1}^{t}+\frac{\Delta t}{\Delta w_{1}} R_{i}
$$

The equilibrium solution converges when more than 100 grid points are used (Figure B1).

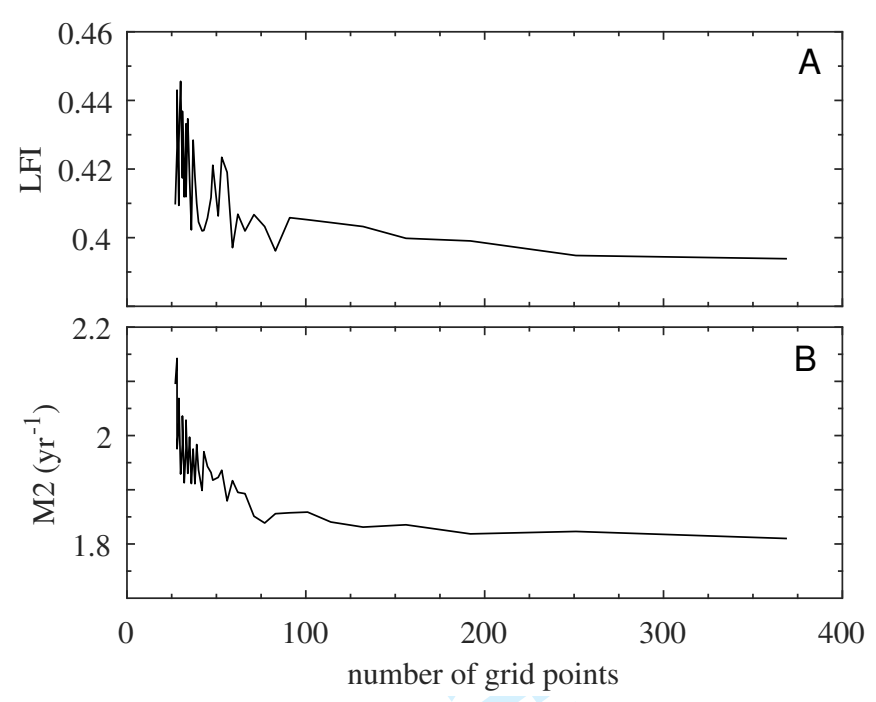

Figure B1: Influence of the number of grid points on the solution of the trait-based model at equilibrium. A) The value of the Large Fish Indicator; B) the predation mortality of individuals with a size of $10 \mathrm{~g}$. 


\section{References for Appendices}

Andersen, K.H., and Beyer, J.E. 2006. Asymptotic size determines species abundance in the marine size spectrum. Am. Nat. 168: 54-61.

Andersen, K.H., Beyer, J.E., and Lundberg, P. 2009. Trophic and individual efficiencies of sizestructured communities. Proc. Biol. Sci. 276(1654): 109-14. doi:

10.1098/rspb.2008.0951.

Hartvig, M., and Andersen, K.H. 2013. Coexistence of structured populations with size-based prey selection. Theor. Popul. Biol. 89: 24-33. doi: 10.1016/j.tpb.2013.07.003.

Houle, J.E., Andersen, K.H., Farnsworth, K.D., and Reid, D.G. 2013. Emerging asymmetric interactions between forage and predator fisheries impose management trade-offs. J. Fish Biol. 83(4): 890-904. doi: 10.1111/jfb.12163.

McGurk, M.D. 1986. Natural mortality of marine pelagic fish eggs and larvae: role of spatial patchiness. Mar. Ecol. Prog. Ser. 34: 227-242. doi: 10.3354/meps034227.

Zhang, L., Thygesen, U.H., Knudsen, K., and Andersen, K.H. 2012. Trait diversity promotes stability of community dynamics. Theor. Ecol. 6(1): 57-69. doi: 10.1007/s12080-0120160-6. 